Smart, P. R., Heersmink, R., \& Clowes, R. W. (2017) The Cognitive Ecology of the Internet In S. J. Cowley \& F. Vallée-Tourangeau (Eds.), Cognition Beyond the Brain: Computation, Interactivity and Human Artifice (2nd ed.). Springer International Publishing, Cham, Switzerland.

\title{
The Cognitive Ecology of the Internet
}

Paul Smart, Richard Heersmink, and Robert Clowes

\begin{abstract}
In this chapter, we analyze the relationships between the Internet and its users in terms of situated cognition theory. We first argue that the Internet is a new kind of cognitive ecology, providing almost constant access to a vast amount of digital information that is increasingly more integrated into our cognitive routines. We then briefly introduce situated cognition theory and its species of embedded, embodied, extended, distributed and collective cognition. Having thus set the stage, we begin by taking an embedded cognition view and analyze how the Internet aids certain cognitive tasks. After that, we conceptualize how the Internet enables new kinds of embodied interaction, extends certain aspects of our embodiment, and examine how wearable technologies that monitor physiological, behavioral and contextual states transform the embodied self. On the basis of the degree of cognitive integration between a user and Internet resource, we then look at how and when the Internet extends our cognitive processes. We end this chapter with a discussion of distributed and collective cognition as facilitated by the Internet.
\end{abstract}

Paul Smart

Electronics \& Computer Science, University of Southampton, Southampton, SO17 1BJ, United Kingdom.

e-mail: ps02veecs.soton.ac.uk

Richard Heersmink

Department of Philosophy, Macquarie University, Sydney, Australia.

e-mail: richard.heersmink@gmail.com

Robert W. Clowes

Instituto de Filosofia da Nova, Faculdade de Ciências Sociais e Humanas, Universidade Nova de Lisboa, Av. de Berna, 26-4 piso, 1069-061 Lisbon, Portugal.

e-mail: robert.clowes@gmail.com 


\section{Introduction}

The Internet has radically altered the way we access information, deeply transforming the way we think, act and and remember. Very few of our cognitive and epistemic endeavors, either individual or collective, are undertaken without some sort of involvement of the Internet: we look up information with search engines, store documents in the cloud, navigate with online maps, read online newspapers and books, engage with online courses, use online recipes, check online timetables, watch online videos, play online games, and so on. In this chapter we conceptualize the Internet as part of our cognitive ecology (see Bateson, 1972; Hutchins, 2010). Cognitive ecologies can be defined as "the multidimensional contexts in which we remember, feel, think, sense, communicate, imagine, and act, often collaboratively, on the fly, and in rich ongoing interaction with our environments" (Tribble and Sutton, 2011, p. 94). In our contemporary digital society (see Lupton, 2015), the Internet constitutes an important part of our cognitive ecology, as most people spend many hours per day interacting with the Internet via TVs, desktop computers, laptops, tablets, smartphones, smartwatches, and other devices.

We agree with Hutchins that "the study of cognitive ecosystems will become an increasingly important part of cognitive science" (Hutchins, 2010, p. 705). This chapter therefore aims to understand the cognitive and epistemic implications of the Internet. It aims to take seriously the Internet as an important part of our cognitive ecology, contributing to human cognition in a variety of ways. Our analysis takes the perspective of situated cognition theory and its species of embedded, embodied, extended, distributed and collective cognition (Robbins and Aydede, 2009). Situated cognition theory is a set of approaches to human cognition underlining the importance of our embodied interactions with the socio-technological environment (Hutchins, 1995; Clark, 1997, 2008; Dourish, 2001; Anderson, 2003; Gallagher, 2005; Menary, 2010; Sutton, 2010; Malafouris, 2013). A situated approach allows us to look at the relationship between the Internet and its users from a variety of viewpoints. It is partly for this reason that we believe this approach is in an especially strong position to help us understand the cognitive contribution of the Internet, as we want to cast our explanatory net as widely as possible. A number of recent works have, likewise, adopted a situated approach when discussing the relation between human cognition and the Internet or World Wide Web ${ }^{1}$. These include Clowes (2015), Halpin (2013), Halpin et al. (2010), Smart (2012; 2014), and Staley (2014) (henceforth the 'Web'). This chapter

\footnotetext{
1 The current chapter uses the term 'Internet' as a catch-all term for all the various applications that are built on top of the Internet. This includes the World Wide Web, which is currently the most popular Internet application. As such, when we refer to the Internet as a cognitive ecology, we mean to suggest that the Web (as well as all other Internet applications, such as email) should be included as part of the cognitive ecology.
} 
builds on and synthesizes these works into an extensive overview and analysis of the cognitive implications of the Internet.

The chapter has the following structure. We start by conceptualizing the Internet as a new kind of cognitive ecology, looking specifically at the Social Web, the Web of Data, mobile computing, human computation, augmented reality, and personal informatics (see Section 2). After that, we outline situated cognition theory, briefly analyzing some of the relations between embedded, embodied, extended, distributed, and collective cognition (see Section 3). We then analyze the Internet in terms of these frameworks. Taking an embedded cognition view, we conceptualize how the Internet shapes certain kinds of cognitive tasks (see Section 3.1). We then look at how the Internet enables new kinds of embodied interaction, extends certain aspects of our embodiment, and (potentially) transforms the embodied self (see Section 3.2). Thereafter, on the basis of the degree of cognitive integration between the user and online information, we analyze the kinds of situations in which the Internet might be said to form a constitutive part of human cognitive processespart of the physical machinery of the human mind (see Section 3.3). We end this chapter with a discussion of distributed and collective cognition as facilitated by large-scale forms of technology-mediated social participation (see Section 3.4).

\section{The Internet: A New Kind of Cognitive Ecology}

Over the past several decades, the Internet has emerged as an important part of the material environment in which human (and perhaps machine ${ }^{2}$ ) intelligence is realized. This view of the Internet ties in nicely with ecological approaches to cognition (see Bateson, 1972; Malafouris, 2013; Hutchins, 2010), which emphasize the role of cognitive ecosystems (i.e., complex networks of material forces and factors that span brain, body and world) in attempts to explain and understand human cognitive capabilities. Hutchins (2010), for example, suggests that our attempt to understand "cognitive phenomena must include a consideration of the environments in which cognitive processes develop and operate" (p. 706). From an ecological perspective, therefore, the Internet can be seen as part of the ecosystem for human cognition: it serves as an increasingly important part of the material environment in which an ever-expanding array of human cognitive and epistemic activities unfold. An ecological perspective also invites something of a methodological and conceptual shift when it comes to analyzing the cognitive effects of the Internet (see Smart, 2013). In particular, by adopting an ecological perspective, it seems appropriate to analyze the Internet from the perspective of approaches that are typically subsumed under the heading of a situated approach to cognition,

${ }^{2}$ Smart (2013), for example, suggests that the Web provides a new kind of ecological context in which advanced forms of machine intelligence might emerge. 
e.g., embedded, embodied, extended and distributed/collective approaches to cognition (see Robbins and Aydede, 2009). Such an approach seems particularly appropriate once we consider some of the current areas of research and development that are shaping the technological trajectory of the Internet and Web. Prominent areas of research attention in the Web and Internet Science (WAIS) community thus include (but are not limited to) the following $^{3}$ :

- The Social Web: Some of the most popular systems on the Web today form part of what is known as the Social Web. These include social networking sites, such as Facebook; microblogging services, such as Twitter; and social media systems, such as Wikipedia and YouTube. The Social Web is currently a major focus of interest for those concerned with issues of collective intelligence and distributed cognition (Hendler and BernersLee, 2010; Malone et al, 2010; Chi, 2009; Chi et al, 2008; Halpin, 2013).

- The Web of Data: The Web is increasingly viewed as a platform that supports the implementation of data-driven apps, services and data analytic capabilities. The use of linked data formats promises to increase the accessibility of online content, as well as enhance the flexibility of digital representations. Such capabilities are sometimes seen as relevant to the emergence of Web-based forms of cognitive extension (Smart, in press, $2012)^{4}$. It is important not to underestimate the transformative impact of the sort of ubiquitous data environment that might be brought into being on the back of the Web of Data. In order to help us see this, consider the way in which the constant stream of data provided by the Global Positioning System (GPS) has changed the nature of human spatial navigation capabilities, with potential repercussions for the neural mechanisms that support spatial cognition (see Maguire et al, 2000) ${ }^{5}$.

- Mobile Computing \& Wearable Devices: Mobile access to the Internet is a key capability area for many technology vendors. A range of mobile Internet-enabled devices are currently available, of which the smartphone is undoubtedly the most popular. Mobility is a key factor in increasing our access to online data and services. It is also central to the emergence of what is sometimes referred to as the 'Embodied Web' (see Matsumoto

3 This represents a subset of all the areas that could have been listed. Other areas of notable interest from a cognitive science perspective include cloud computing (see Clowes, 2015), the Semantic Web (see Smart, in press), and the Internet of Things (see Section 3.1).

${ }^{4}$ In particular, the use of linked data formats helps to separate issues of information presentation from issues of information representation. This kind of 'presentational agnosticism' is crucial when it comes to the flexible (and dynamic) creation of cues, prompts, and affordances that serve to shape the profile of human thought and action (see Smart, in press).

${ }^{5}$ It is also interesting to note the way in which this ubiquitous and ever-present 'data environment' helps to provide new opportunities for the implementation of locationaware intelligent systems, such as driverless cars and aerial drones. 
et al, 2008) - the idea that our interactions with the Web will eventually occur as part of our everyday embodied engagements with a heterogeneous array of material artifacts. The fact that mobile devices, such as smartphones and wearable devices, are becoming so closely associated with the biological body, coupled with the fact that their modes of operation are increasingly linked to our physical movements and physiological processes, highlights the potential relevance of the Internet (and Internet-enabled devices) to issues of material embodiment and embodied cognition (see Section 3.2).

- Human Computation: Human computation is an evolving area of research that seeks to harness human intelligence in the context of computational tasks, especially those whose complexity exceeds the capabilities of existing Artificial Intelligence (AI) algorithms (Michelucci, 2013; Law and von Ahn, 2011). Research in the area of human computation seeks to study the ways in which human capabilities can be integrated into some larger computational processing routine, yielding a form of bio-technologically hybrid computational system. In this case, the Internet often serves as a convenient platform for combining the complementary capabilities of conventional computing systems and human agents. Citizen science is one area where Web-based forms of human computation system are often used to good effect (Lintott and Reed, 2013). Compelling examples of such systems can now be found in a number of scientific areas, including proteomics (Khatib et al, 2011), astronomy (Lintott et al, 2008), and neuroscience (Marx, 2013; Helmstaedter et al, 2013). From the perspective of situated cognition, such research is relevant to issues of distributed cognition and the realization of bio-technologically hybrid forms of machine intelligence (Michelucci, 2016; Smart, 2013).

- Augmented/Mixed Reality: Augmented/mixed reality devices aim to 'embed' digital information in the real world by adding virtual overlays to the real-world environment. Some notable innovations in this area include Google Glass and Microsoft HoloLens. The cognitive impact of such devices has typically been discussed in relation to both embodied (Smart, 2014) and extended cognition (Smart, 2012); however, we can also view technological advances in this area as relevant to issues of embedded cognition (see Section 3.1).

- Personal Informatics \& Personalization: Issues of personalization and the 'quantified self' (see Swan, 2013) are increasingly popular focus areas for WAIS research. Although the majority of research in this area is concerned with personal data stores (Van Kleek and O'Hara, 2014) and self-tracking technologies (Lupton, 2013), there is also considerable interest in the cognitive and epistemic impact of techniques that support personalized access to online information (e.g., Simpson, 2012). Issues of personalization and personal informatics are of interest from the perspective of both extended (Clowes, 2015) and embodied cognition (see Section 3.2). 
As is apparent from this (admittedly partial) list, our near-term future is one in which the Internet is likely to play an ever-more intimate role in shaping the nature of our everyday cognitive activities. Relative to this influence, it makes sense, we suggest, to see the Internet as a important part of the cognitively-potent extra-organismic environment in which our biological brains are now situated. The Internet, in other words, should be seen as a form of cognitive ecology. Not only does this perspective help to establish an important link with ecological approaches in contemporary cognitive science (Hutchins, 2010; Malafouris, 2013; Tribble and Sutton, 2011), it also helps us to think about the creation and modification of online content as a form of 'ecological engineering' (Sterelny, 2003) or 'cognitive niche construction' (Clark, 2008). Every time we upload, annotate, edit, tweet or post, we are all (arguably) engaged in the construction and configuration of an environment that (in return) plays an increasingly important role in shaping the profile of our cognitive and intellectual endeavors ${ }^{6}$.

\section{Situated Cognition Theory}

In the last twenty to thirty years, there has been a shift in the cognitive sciences away from focusing on cognitive processes realized in the brain and towards focusing on cognitive processes involving brain, body, and environment (e.g., Clark, 1997). In The Cambridge Handbook of Situated Cognition, Robbins and Aydede (2009) identify three distinct but related theses that characterize the situated cognition movement. First, the embodied cognition thesis, which claims that cognition depends on, and is sometimes constituted by, the human body (e.g., Gallagher, 2005). Second, the embedded cognition thesis, which claims that our cognitive processes are sometimes shaped but not constituted by bio-external resources (e.g., Rupert, 2004). Third, the extended and distributed cognition theses, which claim that cognitive states and processes, under certain conditions, are distributed across embodied agents and cognitive artifacts or other bio-external resources (e.g., Hutchins, 1995; Clark and Chalmers, 1998). Some theorists take these three approaches as a package deal, whereas others defend only one of these approaches. In this chapter, we do not prioritize one approach over another but see merit in all of

\footnotetext{
${ }^{6}$ Aside from its cognitive and epistemic effects, the Internet also influences the structure and organization of social processes. This raises a wealth of (socio-economic, socio-cultural and socio-political) issues that are the current focus of attention within the social sciences and digital humanities communities (Lupton, 2015; van Dijk, 2012). An in-depth discussion of such issues is beyond the scope of the current chapter; however, it is important to bear in mind that the Internet may sometimes be seen to exert an indirect influence on cognitive processes as a result of its ability to reshape the wider social, political, cultural and economic landscapes in which much of human thought and action takes place.
} 
these approaches as a means to better understand the cognitive implications of the Internet.

Situated cognition theory can thus be seen as the genus and embodied, embedded, and extended/distributed cognition theory as its species ${ }^{7}$. All these approaches have conceptual and metaphysical consequences, since they move beyond an individualist form of cognitivism and towards a picture that involves brain, body, and environment. As a result, these approaches also have methodological consequences: rather than merely focussing on cognitive processes in the brain, they advocate that we should focus on the cognitive relation between the brain, body, and environment, both on a conceptual and empirical level. Therefore, in order to study situated cognitive systems, Clark argues that we need "a new kind of cognitive scientific collaboration involving neuroscience, physiology, and cultural, social and technological studies in about equal measure" (Clark, 2001, p. 154). One of the goals of this chapter is to contribute to Clark's call by conceptualizing human-Internet interactions in light of the different species of situated cognition theory.

The relationship between these three species is not always clear, as there are different versions of each species with claims of various strengths. In the case of embodied cognition, for example, one can make a distinction between weak and strong embodied cognition. Weak embodied cognition claims that human cognitive processes sometimes depend on and are shaped by the body, but are not co-constituted by it. Strong embodied cognition, on the other hand, claims that cognition is partly constituted by the body. It seems that the embedded and extended cognition theses have to incorporate (some version of) the embodied cognition thesis. This is so because one needs to interact bodily with environmental structures and cognitive artifacts in order to scaffold or extend one's cognitive processes. The body thus plays an essential role in embedding or extending cognition. However, one can be an embedded cognition theorist without accepting the strong version of the embodied cognition thesis. So, one can claim that cognitive processes depend on bodily processes and environmental structures, but deny that these are constitutive of cognition. Body and environment are then mere causal input to the brain-bound cognitive system. This relationship is different for extended cognition, which seems to include a strong version of embodied cognition as demonstrated by Clark's phrases "putting brain, body and world back together again" (Clark, 1997) and "where brain, body, and world collide" (Clark, 1999). Here, the body is seen as one of the constitutive elements in a cognitive process that is distributed across brain, body, and the extra-organismic environment. Paul Dourish (2001), for example, is an embodied cognition theorist who is interested in how embodied creatures like ourselves interact with computational

7 Whilst this is a helpful tripartite distinction between species of situated cognition theory, it is not exhaustive. There are other views such as enactivism (Stewart et al, 2010), collective cognition (Smart et al, 2010b) and transactive memory theory (Wegner, 1995) that are also non-Cartesian in that they are concerned with the way a cognitive agent is situated in the environment. 
systems like tangible computing systems. He refers to this as 'embodied interaction'. These kinds of computational systems, however, are not conceived of by Dourish as part of the human cognitive system. Instead, they are seen as resources that shape embodied cognitive processes. As such, Dourish is an embodied cognition theorist who embraces an embedded, but not extended, perspective.

Robbins and Aydede (2009) lump together the extended and distributed cognition theses, as both of these views argue that external resources can be constitutive of cognition. There are, however, important differences between the two views. Hutchins (2014) points out that extended cognition refers to a subset of cognitive events that involve the interaction of internal and external resources. Distributed cognition, by contrast, is a view on all of cognition. So the question is not whether or when cognition is distributed; rather "...the interesting questions concern the elements of the cognitive system, the relations among the elements, and how cognitive processes arise from interactions among those elements...The hypothesis of extended cognition is an important hypothesis within the perspective of distributed cognition" (Hutchins, 2014, p. 36) [emphasis added]. Distributed cognition is thus a much broader view than extended cognition. Furthermore, extended cognition is 'organismcentered' in the sense that it sees the biological (human) agent as playing a crucial role in the assembly, maintenance and monitoring of extended cognitive circuits (see Clark, 2008, p. 139). Distributed cognition theory, in contrast, does not assume that humans are necessarily the center of distributed systems. "Centers and boundaries are features determined by the relative density of information flow across a system", suggests Hutchins (2014, p. 37). This marks an important difference between extended mind theorists and the proponents of so-called distributed cognition. Extended mind theorists, such as Clark (2008), emphasize the crucial role of the biological brain in the assembly of extended cognitive systems. This, as Clark notes, leads to the idea that cognition is organism-centered, even if it isn't always organism-bound. Distributed cognition theorists, such as Hutchins (2011), tend to object to this organism-centered view. They worry that "by stressing the pivotal role of the brain in the recruitment of external resources and in the maintenance of resource-engaging cycles, [the extended mind theorist] actually gives too much away to a traditional internalist vision" (Clark, 2011, p. 451).

Much of the research into distributed cognition has typically focused on socio-technical systems that involve the interaction of (multiple) human agents with non-biological props, aids and artifacts (Hutchins, 1995). Given that many kinds of Internet-based systems are ones that feature a combination of social and technological elements, it seems that the Internet might be a natural place to look for instances of distributed cognizing. As already mentioned, however, the use of the term 'distributed cognition' is apt to cause confusion. It might seem, for example, that by using the term distributed cognition we are referring to a particular form of cognition, one that is, in this case, realized by multiple individuals acting in concert with an array of 
non-biological props, aids and artifacts. Recently, however, Hutchins (2014) has suggested that this is the wrong way to view the notion of distributed cognition. "Distributed cognition," he suggests, "is not a kind of cognition; it is a perspective on all of cognition" (p. 3). The term 'distributed cognition' is thus equally applicable to cases of brain-based cognizing and to forms of cognition that occur in the context of larger hybrid ensembles consisting of both biological and non-biological elements. In view of this, we suggest that the term 'collective cognition' is a more appropriate way to characterize the cognitive processing that occurs in socially-distributed contexts, irrespective of whether or not the relevant information processing loops involve technological or artifactual mediation. Such a move may seem undesirable, especially if one regards the term 'collective cognition' as referring solely to systems in which multiple individuals participate in face-to-face exchanges. Giere (2007; 2012), for instance, attempts to make a distinction between what he calls "full-blown distributed cognition" and "mere collective cognition" (Giere, 2007 , p. 1). In particular, he suggests that systems in which instruments and other artifacts form parts of a cognitive system should not be seen as instances of collective cognition. Instead, he suggests that we should limit the term 'collective cognition' to situations in which multiple human agents are working together. It will be clear, however, that the way in which Giere (2007; 2012) interprets the term 'distributed cognition' is in some conflict with the view adopted by Hutchins (2014). In addition, we should perhaps question the extent to which it is actually possible to distinguish between cases of distributed and collective cognition in the manner suggested by Giere. One potential problem, here, is that even in face-to-face contexts it does not seem entirely appropriate to grant that no form of artifactual mediation is taking place. Human social exchanges are typically mediated by linguistic symbols of either the verbal or orthographic variety, and these sorts of symbolic representations are sometimes referred to as artifacts. Clark (1997, chap. 10), for example, suggests that we should see public language as the 'ultimate artifact', as a kind of tool that "enables us to reshape a variety of difficult but important tasks into formats better suited to the basic computational capacities of the human brain" (p. 193). In view of all this, we will use the term 'collective cognition' to refer to systems of multiple agents that participate in cognitive tasks (i.e., tasks that are typically glossed as cognitive in nature), irrespective of whether or not these systems involve technological or artifactual mediation.

Having thus briefly analyzed some of the relations between the species of situated cognition theory, we now point out two important topics in situated cognition theory, namely (1) the size of the unit of analysis and (2) whether an external resource is constitutive of a cognitive state, process or system. Some theorists focus on small scale systems comprising a single embodied agent interacting with a cognitive artifact (Clark, 2008; Kirsh and Maglio, 1994), or two people interacting with each other, thereby forming a transactive memory system (Sutton et al, 2010; Wegner, 1995). Others focus on 
larger systems consisting of many embodied agents interacting with a number of artifacts such as a team of navigators on a ship (Hutchins, 1995), a group of scientists working in a laboratory (Nersessian, 2009), or larger social groups such as sport teams (Williamson and Sutton, 2014; Theiner et al, 2010). In this chapter, our units of analyses are both single embodied agents interacting with the Internet as well as collections of such agents. We also look at systems where online information is merely scaffolding cognition and where it is potentially integrated deeply into the cognitive processes of their users, thereby extending their cognitive processes.

\subsection{Embedded Cognition}

Unlike the notion of extended cognition, which sees elements of the extraorganismic environment as sometimes playing a constitutive role in the realization of cognitive states and processes, the notion of embedded cognition rejects the idea that the boundaries of cognition extend beyond the traditional biological borders of the human agent. Embedded cognition theorists thus focus on how artifacts and other external resources aid, but do not constitute, our cognitive systems (e.g., Rupert, 2004). In this subsection, we look at how the Internet aids and shapes our cognition.

Throughout the evolution of our cognitive system, our minds have depended heavily on material culture (Gregory, 1993; Vygotsky and Luria, 1994; Donald, 1993). Lambros Malafouris (2004; 2013) argues that tools and other human-made objects are the conditions of possibility for a range of cognitive operations which we often too carelessly attribute to our biological heritage. The invention of written language, calculation devices, maps, the printing press, and other cognitive technologies have augmented and shaped our cognitive capacities. The Internet, on this view, is just the latest in a long history of cognition shaping and enabling tools, opening some cognitive spaces and perhaps closing some others.

Due to the Internet, we are currently living through important changes in the material (and digital) culture of memory, as an increasingly varied range of digital devices provide E-Memory adjuncts to, and extensions of, our biological resources. E-Memory can be defined as digital systems, devices and services that "we use to record, store and access digital memory traces to augment, re-use or replace organismic systems of memory" (Clowes, 2013, p. 107). Research in cognitive psychology appears to show that human cognition is already factoring in the presence of E-Memory resources. In cases where a computer file is believed to remain available in the future, there is a tendency for our biological memory systems to remember the location rather than the contents of the file (see Sparrow et al, 2011). If this is a general indication of how our brains deal with ambient information stores, it is likely they are already being restructured by constantly accessible online systems. 
It is still undetermined how much our biological memories are affected by the cognitive affordances of the Internet and much more empirical data is needed. However, it is clear that we are becoming ever-more accustomed to using search technologies to recall facts and settle arguments. As we lean evermore heavily on these technologies our basic habits of mind and thinking are undergoing significant changes.

When some theorists (e.g., Carr, 2010) bemoan that human cognition is under threat from a host of new Internet technologies, they tend to forget that it is not a pristine human mind which is under threat from technology, but rather an artifact-dependent mind faced with the adaption and accommodation to a new set of technologies (Donald, 1993). In Clark's words, we have always been "natural-born cyborgs" (Clark, 2003). However, it is clear that E-Memory has a range of properties which make it very different from previous epochs of memory technology. For this reason, E-Memory potentially has different effects on our cognitive systems.

Using previous external memory systems such as tying knots in a string, making marks in clay, or maintaining written records tended to be effortful tasks and ones where storage capacity was finite (Mayer-Schönberger, 2011; Donald, 1993). E-Memory, in contrast, can record vastly more than previous regimes of technology. In principle, we can now store and retrieve a lifetime's worth of high resolution video and sound (Gemmell and Bell, 2009; Gemmell et al, 2006). Gordon Bell calls this phenomenon "total recall". Additionally, recording, and to an extent accessing, E-Memory traces has become a relatively effortless task for an individual equipped with a smartphone. This suggests that Internet-mediated E-Memory will have a very different informational profile to past memory technologies. As we come to efficiently and unthinkingly rely upon the Internet, the human cognitive profile is likely to undergo significant changes. Much will depend on how our flexible cognitive architecture accommodates to the new environment. The uses of E-Memory we have so far discussed are largely mediated by personal mobile devices we carry with us. The growing trend, however, is for the wider material environment to become augmented with Internet-mediated technologies. We are deliberately re-designing the material world to be "smarter".

Given that embedded cognition recognizes the role of extra-organismic factors in shaping human cognitive processes, it should come as no surprise that there are many of points of interest for the embedded cognition theorist attempting to understand the cognitive implications of the Internet. In fact, practically all the features of the Internet ecology that surface in relation to embodied, extended and collective cognition also come into focus when we view the Internet through the lens of embedded cognition. There are, however, a number of specific points of interest for the embedded cognition theorist. These relate to the way in which the Internet of Things (IoT) and augmented reality technologies are able to alter the features of the physical (and virtual) environments in which we human agents are materially embedded. 
The aim of the IoT initiative is to equip a variety of everyday physical objects with data acquisition, data processing and data exchange capabilities (Greengard, 2015; Miller, 2015). In addition, the IoT tends to view the environment as something of a cooperative partner with respect to the performance of a multitude of different tasks. Crucially, the IoT promises to deliver the kinds of capabilities that are often alluded to in discussions of ubiquitous computing (Weiser, 1991) and ambient intelligence (Weber et al, 2005). The general idea is that by extending the reach of the Internet to the elements of our physical environment, we are able to transform the environment into something that is highly responsive to our needs and supportive of our thoughts and actions. This is the guiding principle behind current work that seeks to develop a seemingly endless array of 'smart things'. These include, for example, smart TVs, smart cars, smart buildings, smart cities, and, of course, smart environments (see Miller, 2015). From the perspective of embedded cognition, the IoT promises to alter the nature of our interactive engagements with the external environment, thereby influencing the kinds of dependencies that are deemed to shape brain-based forms of cognitive processing. In particular, we can see the advent of the IoT as part of an attempt to structure the environment in ways that enhance our biologically-based capabilities.

As a concrete example of the way in which the IoT may help to shape human cognition, consider the case of prospective memory. Prospective memory is a form of memory that involves "remembering to carry out intended actions without being instructed to do so" (Baddeley et al, 2009, p. 343). The case of an individual who needs to remember to defrost the meat by removing it from the freezer when they return home from work serves as a typical example of prospective memory. Such forms of memory are, of course, relatively commonplace, and they are pretty much indispensable in terms of our ability to coordinate our lives effectively - a fact that is all too sadly evidenced by those suffering from impairments in prospective memory (see Woods et al, 2008). As has been pointed out by a number of commentators (e.g., Staley, 2014, pp. 36-37), the advent of smart environments provides a range of opportunities to reshape the nature of prospective memory. Staley (2014), for example, talks of smart devices being used to implement prospective memory systems that allow individuals to 'embed their intent' within specific environments, such as within their home or office. An individual could thus be reminded of the need to engage in particular actions (e.g., to remove the meat from the freezer) whenever they are suitably placed to perform these actions (e.g., when they first enter the kitchen upon returning home from work $)^{8}$. Prospective memory is also embedded in the mobile devices that we carry around with us. We can expect these devices to exhibit ever-greater levels

\footnotetext{
8 Note that inasmuch as we see prospective memory as a form of memory in which we perform future actions without explicit instructions (see Baddeley et al, 2009), it is unclear to what extent we should regard reminder systems as implementing a form of (external) prospective memory.
} 
of contextual sensitivity, e.g., reminding us to check our shopping list as we pass a grocery store. Relying on such devices to structure our activities can be seen as partially outsourcing human agency to our devices. However, this need not be seen as undermining our agentive powers. Instead, it can be seen as continuing a long history of using devices to structure, support and (even) generate complex aspects of human agency (see Neumann and Cowley, 2013, for further discussion).

Aside from the IoT, another focus of interest for the embedded cognition theorist relates to the development of augmented and mixed reality devices. These devices (the exemplar of which is Google's Project Glass) support the creation of virtual overlays that are superimposed on the real-world environment. A crucial point of interest, here, concerns the way in which such devices can be seen to modify the properties of the environment in which cognition occurs. By generating an array of virtual representations, augmented reality devices are able to alter the 'effective' structure of the local environment, expanding the array of informational cues and affordances that can be used to guide cognitive processing. The inherent flexibility of these 'virtual designer environments' ${ }^{9}$ means that future generations will have an unprecedented opportunity to rapidly reconfigure the structure of their environments in ways that complement, supplement or perhaps even supplant their brain-based cognitive capabilities.

\subsection{Embodied Cognition}

Although there are a number of different views as to what is implied by the term 'embodied cognition', a common feature of embodied cognition research is the emphasis that is placed on extra-neural bodily factors in shaping the course of cognitive processing (Anderson, 2003; Shapiro, 2007, 2011). Typically, research into embodied cognition emphasizes the way in which an organism's bodily structure or physical actions help to constrain (and sometimes constitute) cognition. A somewhat trivial example is provided by the way in which the placement of an organism's sensory apparatus (the position of their eyes and hears) helps to structure the incoming sensory array in ways that support perceptual processing (Webb, 1996). Other research focuses on the ways in which dynamically evolving motor state variables can help to guide the expression of intelligent behavioral responses (e.g., McBeath et al, 1995). More complex forms of embodied cognition research come in the form of work that seeks to evaluate the role of physical actions (e.g., hand gestures)

\footnotetext{
9 This notion of a 'virtual designer environment' builds on the notion of a 'designer environment' as discussed by Clark (1997): "We build 'designer environments' in which human reason is able to far outstrip the computational ambit of the unaugmented biological brain" (Clark, 1997, p. 191).
} 
in supporting various forms of human cognitive competence (Goldin-Meadow, 2003).

At first sight, it might appear that a discussion of embodied cognition is somewhat out of place in a chapter that focuses on the role of the Internet in shaping our cognitive profile. After all, work in embodied cognition tends to focus on situations in which we are actively engaged with the real world, exploiting all manner of sensorimotor cues in order to realize intelligent thought and action. The nature of our interaction with the Internet seems far removed from this sort of situation. Although we might be justified in seeing the Internet as an important part of the context in which cognition occurs - part of the material backdrop against which our thoughts and actions take shape - it is by no means clear that the details of our physical embodiment really matter that much when it comes to understanding the cognitive consequences of our online interactions.

There are, in fact, a number of ways in which the Internet impacts on issues that lie at the heart of the embodied cognition research programme. Firstly, as noted by Smart (2014), the advent of mobile and portable computing solutions is progressively altering our sense of what it means to engage with the online world. In place of conventional forms of interaction, in which we interact with the Internet via a browser interface while seated at a desktop computer, it is increasingly common for us to engage with the Internet as part of our embodied interactions with the wider physical environment. Mobile devices, such as smartphones, for example, enable us to interleave our interactions with the Internet and the real world in a way that seems to blur the traditional distinction between 'offline' and 'online' modes of interaction (see Floridi, 2011, 2014). In addition, as new kinds of Internet-enabled device become available, so the palette of physical actions and gestures that we use to interact with the Internet is expanding. Touchscreens have clearly played an important role, here, with swiping and zooming emerging as more-or-less standard parts of our gestural lexicon. Other kinds of interactivity aim to capitalize on the way in which we typically interact with a common array of physical artifacts and objects, helping to support forms of 'embodied interaction' (see Dourish, 2001) with the online world. Consider, for example, work by Matsumoto et al. (2008) to develop a Web-enabled umbrella. The umbrella features a variety of sensors (e.g., GPS, compass, accelerometer, etc.), and it is able to project Web-based content directly into the user's field of view by virtue of a projection device focused on the underside of the umbrella canopy. By providing the user with a range of interaction opportunities (e.g., the normal turning, dipping, and twisting actions that people perform with umbrellas) and by also integrating information from a variety of sensors and Web services, the umbrella is able to present a variety of forms of contextrelevant information that take into account both the user's physical location, as well as their current interests and activities. Of particular interest in the current context, Matsumoto et al. (2008) describe their work as part of an effort to realize what they call the 'Embodied Web': a form of enhanced inter- 
activity in which natural embodied interactions are used to interact with the Web and "make our experience in the real world more engaging and active" (Matsumoto et al, 2008, p. 49).

A second way in which notions of embodied cognition are relevant to understanding the cognitive significance of the Internet comes in the form of what might be referred to as 'the extended body'. The idea, here, is that (in certain cases) it may make perfect sense to see Internet-enabled devices as literal prosthetic extensions of an individual's biological body. If this idea seems to strange or unpalatable to you, perhaps it will help to reflect on what it is that makes something a genuine body part. One possible answer to this question focuses on the way in which our bodies work to mediate our sensorimotor engagements with the world. Our ears therefore count as part of our body because they assist with the transduction of certain kinds of energetic fluctuation in the ambient environment; our legs count as part of our body because of the way in which they service our locomotory objectives; and our teeth count as part of our body because of the way in which they enable us to physically prepare certain kinds of matter for the processes of digestion and absorption. Note that an appeal to the biological nature of the candidate bodily elements will not suffice here. Should a cochlear implant, a prosthetic limb or a tooth implant fail to count as part of our body simply because they are not biological in nature? And what about the 'bodies' of smart cars and mobile robots ${ }^{10}$ Do these systems fail to have a body simply because they are not biological systems? The answer to these questions is surely a resounding 'no'. And once we drop appeals to biology in determining what it is that makes something a part of the body then the path is clear for a more functionally-oriented conception of the body. Crucially, once we have this functional view to hand, it becomes possible to consider non-biological resources as literal extensions of the biological body: providing a non-biological element plays the same sort of functional role as a conventional (biological) body part, then it seems we should treat that non-biological element as a genuine part of the body. This, of course, opens the door to cognitivelypotent forms of 'corporeal incorporation' involving a variety of non-biological resources.

One example of a functionally-oriented conception of the body is provided by Clark $(2008 ; 2007)$. He suggests that we should identify the body with whatever it is that just so happens to serve as the "locus of willed action, the point of sensorimotor confluence, and the stable (though not permanently fixed) platform whose features and relations can be relied upon (without being represented) in the computations underlying some intelligent

10 Importantly, issues of embodiment often surface in the context of research into cognitive robotics (see Pfeifer and Bongard, 2007). This highlights the importance of a non-biological conception of the body to embodied cognitive science: in the absence of such a conception it becomes difficult to adopt a unified perspective of research into a rich variety of materially-diverse (e.g., biological, robotic and virtual) embodied cognitive systems (see Smart and Sycara, 2015). 
performances" (Clark, 2008, p. 207). The claim, in essence, is that we should identify the body with whatever it is that is playing the sort of role that our biological body typically plays with respect to the genesis and organization of intelligent behavior. Inasmuch as we accept this claim, then it seems that forms of bodily extension that involve our current arsenal of portable and mobile Internet-enabled devices are a realistic possibility. In other words, there seems to be no principled reason why Internet-enabled devices should not be counted as, on occasion, functioning as literal body parts. The only question, of course, is to what extent such devices actually are apt for bodily incorporation. This is an issue that must appeal to the nature of our interaction with Internet-enabled devices, specifically the extent to which such forms of interaction satisfy the sort of functional criteria alluded to by (e.g.) Clark (2008). If we accept that Internet-enabled devices do actually function as literal body parts - as prosthetic technological extensions that enable us to sense, manipulate, exploit, and alter the online world - then there seems to be no clear reason why such devices should not be of relevance and interest to embodied cognitive science ${ }^{11}$. This is because embodied cognition is concerned with the way in which bodily forces and factors influence cognition. When technological resources become bodily protheses that may also (qua embodied cognition) function as cognitive prostheses. This is particularly so when such prostheses are recruited as part of our cognitive and epistemic endeavours.

A variety of sources of (largely circumstantial and anecdotal) evidence support the idea that issues of bodily extension may be relevant to a range of Internet-enabled devices, most notably those that we carry around with us (e.g., smartphones), or those that we attach to the biological body (e.g., smartwatches). Recent trends in technology development are thus largely consistent with what Biocca (1999) refers to as 'progressive embodiment', the idea that technological advances entail the "steadily advancing immersion of sensorimotor channels to computer interfaces through a tighter and more pervasive coupling of the body to interface sensors and displays" (Biocca, 1999 , p. 5). Irrespective of whether we accept that the boundaries of the human mind are moving outwards (see Clark and Chalmers, 1998), it appears that our technologies are progressively reaching inwards, attempting to establish ever-more intimate associations with the elements of the biological body (see Lynch, 2014). Our emerging panoply of portable devices are thus not just forms of smart machinery, they are also (potentially at least) forms of 'intimate machinery'.

\footnotetext{
11 The thing that is important to remember, here, is that inasmuch as a non-biological resource counts as part of an organism's body, then (relative to the claims made by proponents of embodied cognition) the resource is (potentially) poised to play a role in shaping that organism's cognitive processing routines. As a result, if an Internetenabled device counts as a part of the body (on the basis of functional criteria), then it seems that it should be just as much a focus of analytic attention for the proponent of embodied cognition as should a more conventional (i.e., biological) body part.
} 
The mobile phone has, of course, been a popular focus of attention when it comes to issues of bodily extension. Drain and Strong (2015), for example, suggest that the smartphone "becomes incorporated within the assemblage of bodily appendages, environmental features, and artifacts that we encounter in everyday life, to the point where the phone can be considered as a prosthetic extension of ourselves" (p. 190). A number of studies have also revealed that users often regard their mobile phones as extensions of their 'self' or body (Oksman and Rautianen, 2003b,a; Gant and Kiesler, 2001). Perhaps such results should not come as a surprise given the way in which many individuals now relate to their mobile phones. To an ever-greater extent, the smartphone is an indispensable instrument that enables the individual to negotiate the various social, cognitive and epistemic challenges that they confront as part of their daily life (Drain and Strong, 2015; Miller, 2014). This is often reflected in the kinds of deep emotional attachment that people have with their mobile devices (Miller, 2014). As Vincent et al. (2005) note "for some people [their mobile device] has become almost an extension of their body as they hold and fondle the device even when the device is not in use" (p. 72).

One further line of research that may be relevant to claims regarding the bodily incorporation of Internet-enabled devices comes from a study by Salerno et al. (2012). Salerno et al. (2012) sought to investigate the neural processing of self- and other-related stimuli using a trans-cranial magnetic stimulation technique. As part of their experimental protocol, human subjects were presented with four kinds of images. These showed 1) the subject's own hand, 2) the hand of another human subject, 3) the subject's own mobile phone, or 4) the mobile phone of another person. Interestingly, Salerno et al. (2012) observed similar neurological responses when subjects were presented with images of both their own hands and their own mobile phones (i.e., self-related stimuli). However, these responses were distinct from those elicited by the images of 'other-related' stimuli (i.e., the hands or phones of other people). Although the psychological significance of these results is unclear at the present time, Salerno et al. (2012) note that issues of bodily extension may be relevant to their findings. Interestingly, the effects observed by Salerno et al. (2012) were specific to the right hemisphere of the brain. This is consistent with neuropsychological research indicating that the right brain hemisphere is important to a sense of body ownership, with damage to the right hemisphere resulting in a form of 'disownership' of particular body parts (Aglioti et al, 1996; Vallar and Ronchi, 2009). Aglioti et al. (1996), for example, report the case of a woman with damage to the right hemisphere who denied ownership of her left hand and associated 'extracorporeal' objects, for example, the rings that were typically worn on her left hand. Summarizing their results, Aglioti et al. (1996) suggest that "the mental image of one's body may include inanimate objects which [have] been in contact or in close proximity with the body itself" (p. 293). They go onto claim that their findings can be interpreted as providing support for the notion of an 'extended body schema', in which extra-corporeal objects become incorpo- 
rated into the neural processes that mediate a sense of one's body and its capacities for action.

In addition to issues of embodied interaction and bodily extension there is a third way in which notions of embodied cognition may prove useful in enabling us to track the cognitive impact of Internet-related technologies. The main point of interest, here, relates to the way in which new technologies are reshaping the kind of opportunities that we have to track our bodily states and actions. Wearable technologies thus provide not just a means to transform the kind of contact we have with the online world, they also transform the kind of relationship we have with ourselves (see Lupton, 2015). Crucially, as wearable technologies become more sophisticated, they often become more capable of sensing physiological and behavioral states that enable them to contextualize their modes of operation in novel ways. Many contemporary devices already feature this kind of context sensitivity. For example, when I am located in New York, and I wish to visit a particular museum, I can rely on the GPS capabilities of my Internet-enabled device - an iPhone let's say - to adapt its information retrieval processes in a manner that is germane to my current interests. The device, we can assume, is sensitive to my geographic location in a way that enables it to return information that is likely to be directly relevant to my immediate needs and concerns. A similar form of context sensitivity is likely to become possible with future wearable technologies. In this case, however, the devices are likely to factor in a far richer range of cues and affordances than is possible with today's technology. Importantly, by being able to monitor body-related information it becomes possible for this new suite of devices to sensitize their operation to factors that are more directly relevant to our cognitive and epistemic activities. Consider, for example, work by Koriat and Nussinson (2009) to investigate the physiological correlates of the feeling of knowing. They report that the tension of the corrugator muscle can be used to detect the subjective experience we have when we feel we know something. Inasmuch as future devices are able to track physiological signals that index a variety of epistemic feelings (such as the feeling of knowing or the feeling of difficulty) (see Michaelian and Arango-Muñoz, 2014), it is possible that future technologies may be able to adaptively modify their modes of operation to support human end-users with regard to a variety of epistemically-related activities ${ }^{12}$.

The use of technology to record or track personal information is a central element of work that goes under the heading of the 'quantified self' (Lupton, 2013; Swan, 2013). This is a term that is used to refer to any form of self-tracking activity, where the information that is typically tracked is of a biological, behavioral or environmental nature. Current forms of self-tracking

12 A similar point is made by Kunze et al. (2013). They suggest that the use of mobile sensing technologies portends an era in which technology is able to recognize and monitor various forms of cognitive activity, revolutionizing our understanding of the factors that contribute to optimal cognitive performance, as well as providing new ways for technology to shape and scaffold our cognitive routines. 
include the recording of body weight, energy levels, time usage, sleep quality, health, cognitive performance, athletic performance, and learning strategies (Swan, 2013). Clearly, not all these forms of self-tracking are ones that need to rely exclusively on Internet-enabled devices; nevertheless, an increasing number of devices are becoming available that attempt to automate or facilitate self-tracking efforts. As Swan (2013) notes:

"An increasing number of new personal data streams are being generated through quantified self tracking devices, biosensors, wireless Internet of Things devices, health social network data, and social media data. Additional personalized data streams from consumer EEGs, eye-tracking and emotion measurement could be coming in the future" (p. 91).

The significance of Internet connectivity, here, is that it enables personal information to be stored online and subjected to forms of online (e.g., cloudbased) manipulation and processing. Such forms of online processing are often essential when it comes to the analysis of personal data, especially when one considers the quantity of data that can be generated by (e.g.) heart rate sensors. It should also be relatively clear that by placing information online, personal data is often made more amenable to large-scale forms of statistical analysis that can provide potential insights into (e.g.) health-related phenomena. The public availability of self-tracking data is thus a potential boon to epidemiological and clinical research, supporting analyses into factors related to disease onset and progression ${ }^{13}$.

One of the implications of the quantified self is that it provides a greater degree of awareness regarding one's bodily states and processes. Self-tracking technologies are thus sometimes seen as a means of creating a digital dashboard for the biological body, enabling individuals to tap into a wealth of previously inaccessible data. Some writers thus talk about self-tracking devices as supporting the emergence of technological 'exosenses' that extend the reach of the body's sensory capabilities:

"...the quantified self may become additionally transformed into the extended exoself [i.e., a suite of exosenses] as data quantification and self-tracking enable the development of new sense capabilities that are not possible with ordinary senses. The individual body becomes a more knowable, calculable, and administrable object through QS [quantified self] activity, and individuals have an increasingly intimate relationship with data as it mediates the experience of reality" (Swan, 2013, p. 85).

The general idea, therefore, is that self-tracking affords a new way in which body-related information can come to influence the course of cognitive processing. In particular, by virtue of their ability to make body-related information explicitly accessible and perceptible through the other senses ${ }^{14}$, the

13 For example, personal data could be used to evaluate hypotheses concerning the links between sleep patterns and the etiologic bases of diabetes (Tasali et al, 2008), depression (Landsness et al, 2011) and dementia (Sharma et al, 2015).

14 This is sometimes referred to as para-synthetic expression (Won et al, 2015). 
vision of the quantified self opens the door to forms of embodied cognition in which issues of technological mediation are of critical importance. It has long been known, for example, that individual cognitive and emotional responses can be shaped by the explicit perception of physiological signals (e.g., Valins, 1966). In view of this, it seems entirely possible that future technologies could play an important role in determining the role of bodily states and signals in influencing our everyday thoughts and actions at both an individual and social level (see Janssen et al, 2010) ${ }^{15}$. This is, of course, an issue that lies at the heart of contemporary work in embodied cognitive science.

\subsection{Extended Cognition}

Having looked at how the Internet aids some of our cognitive processes and how it relates to human embodiment, we now continue by conceptualizing how it may extend our cognitive states and processes. Extended mind theory takes a systems perspective on the relation between a cognitive agent and the social and material environment in which that agent is situated. In essence, the extended mind is a claim about the location of the material substrate on which cognitive states and processes supervene. It is thus a metaphysical claim with epistemological and methodological consequences.

John Sutton (2010) distinguished between two waves of extended mind theorizing. The first wave argues for the parity of internal and external resources (Clark and Chalmers, 1998), whereas the second wave argues for the complementarity of internal and external resources (Heersmink, in press, 2015; Sutton, 2010). Sutton argues that external resources are often not on a par with internal resources. In the case of memory, for example, internal memory systems are dynamic, integrative and subject to degradation of their traces, whereas external information is often static, not integrated with other information and not subject to degradation. The complementarity view, as formulated by Sutton, reads as follows:

"In extended cognitive systems, external states and processes need not mimic or replicate the formats, dynamics or functions of inner states and processes. Rather, different components of the overall (enduring or temporary) system can play quite different roles and have different properties while coupling in collective and complementary contributions to flexible thinking and acting" (Sutton, 2010, p. 194).

Relative to this view, we can see that external resources need not replicate internal resources; instead, they can have different properties, functions and formats to those of the biologically-based cognitive system. It makes much

15 Explicit access to physiological information (e.g., heart rate) can also, on occasion, influence our sense of body ownership concerning a non-biological appendage (see Suzuki et al, 2013). 
more sense to rely upon and recruit external resources when they do something different from our native or biological capacities. Jointly, an embodied brain plus a complementary resource is a much more versatile and powerful cognitive system than just an embodied brain without any external aids. Wilson and Clark (2009) also defend a complementarity view. They write:

"Contrary to any requirement of fine-grained similarity then, what the friends of extended cognition actually expect, and study, are hybrid processes in which the inner and the outer contributions are typically highly distinct in nature, yet deeply integrated and complementary" (Wilson and Clark, 2009, p. 72).

The cognitive integration of an embodied agent and a resource with complementary properties and functions is thus important for better understanding extended cognitive systems. However, most of the current discussion on extended cognition and the Internet focuses on whether the Internet satisfies Clark and Chalmers' (1998) conditions of reliability, trust, accessibility and past endorsement (Clark, 2008; Smart, 2012, in press; Ludwig, 2015). These conditions are often referred to as the "trust and glue" criteria, and they are typically seen as part of the first wave of extended mind theorizing. The Internet is often seen as failing to meet these criteria ${ }^{16}$. Clark and Chalmers (1998), for example, suggest that "The Internet is likely to fail on multiple counts, unless I am unusually computer-reliant, facile with the technology, and trusting, but information in certain files on my computer may qualify" (p. 18). In a later, co-authored publication, however, Clark says: "Perhaps external representations on the Web, when integrated appropriately into the processes that govern an agent's behaviour, may count as part of that agent's cognitive architecture" (Halpin et al, 2010, p. 2).

So, to better understand human-Internet interactions in terms of extended cognition theory, we need to focus on what "integrated appropriately into the processes that govern an agent's behaviour" means. We suggest that cognitive integration between an agent and the Internet is a multidimensional phenomenon. Some of the relevant dimensions include the kind and intensity of information flow between an agent and the Internet, the accessibility of information, the durability of agent-Internet couplings, the amount of trust a user

16 Problems with trust often lie at the root of these concerns. Clark (2010), for example, claims people do not trust online content to the same extent that they trust information retrieved from bio-memory. From an empirical perspective, however, it is far from clear that people really do subject online information to the sort of evaluative scrutiny that would undermine its candidacy for cognitive incorporation (see Smart, in press). In addition, there a variety of reasons to suspect that at least some sources of online content can be implicitly trusted. Individuals may, for example, rely on the use of cloud-based personal data stores (see Van Kleek and O'Hara, 2014) as a source of trusted information. They may also exploit a range of so-called 'online reliability indicators' (Smart and Shadbolt, in press) to guide metacognitive processes relating to information selection and endorsement (Arango-Muñoz, 2013). Interestingly, processes that give rise to these indicators can, on occasion, be cast as a form of collective or distributed cognition. Ben-Naim et al. (2013), for example, present a distributed approach to the construction of (social) trust metrics, which are subsequently used guide decisions relating to the endorsement of expert recommendations. 
puts into online information, the degree of transparency-in-use that is encountered, the ease with which the information can be interpreted, the amount of personalization that has been undertaken, and the amount of cognitive transformation introduced as a result of the bio-technological merger (Sterelny, 2010; Heersmink, 2015, in press; Menary, 2010; Sutton, 2006). The way we interact with online information may vary along all of these dimensions; however, the higher an agent-Internet system ranks on these dimensions, the denser the integration between the agent and the online information, and the easier it becomes (we suggest) to regard the agent-Internet system as engaging in a form of extended cognition. In this respect, it is interesting to note that the general thrust of technology design seems to be largely in favor of the emergence of cognitively-potent forms of bio-technological merger (see Smart, in press). Of particular interest, are a range of technologies that target our mnemonic capabilities (Clowes, 2015). We thus use our mobile devices to store a lot of personalized information in the cloud and on the Internet, including appointments, birthdays, shopping-lists, sketches, annotated documents, to-do lists, notes, reminders, bookmarked timetables, and so on. The kinds of technologies that are used to interact with such online sources of information (e.g., mobile, portable and wearable devices) arguably serve to enhance the intensity of information flow between agent and the Internet, the accessibility of information, the amount of trust a user puts into the information, the degree of transparency-in-use, the ease with which the information can be interpreted, and the amount of personalization. For these reasons, the information is much more deeply integrated into the cognitive processes that govern our behavior, and it is therefore easier to see it is part of an extended cognitive system.

The way in which information is represented on the Internet may be of particular relevance when it comes to understanding the profile of humanInternet interactions. In particular, the transition to what has been referred to as the Web of Data (see Section 2) may play an important role in enabling Internet resources to be more closely integrated into everyday cognitive processing routines. Smart (in press; 2012), for example, suggests that the transition from a Web of Documents to a Web of Data plays an important role in enabling the Web to function as a component of bio-technologically hybrid cognitive systems. One reason for this concerns the accessibility of specific items of information - the fact that it is possible to retrieve isolated pieces of information in a wide variety of different task contexts. Another reason relates to the fact that content on the Web of Data becomes much more amenable to machine-based processes that can find, filter and format data in ways that are optimally suited to a human end-user's specific information needs and concerns (this is deemed to enhance the accessibility and functional poise of online information). Finally, the move away from the Web of Documents to the Web of Data opens up a range of presentational capabilities that can be used to guide thought and action in particular ways. Thus, when we think of the cognitive impact of new devices, such as Google's Project Glass and 
its successors, we should not necessarily think of their presentational capabilities as being limited to the display of conventional Web pages. Instead, we should think of a whole variety of different data-driven presentational capabilities, some assuming the form of simple natural language statements and instructions, others relying on the use of graphical cues, prompts and affordances. In addition, the notion of augmented, mixed or blended reality enables us to think of Internet-based information being used to create virtual overlays on the physical environment, enriching the kinds of environmental structures to which our brain-based processing routines are already attuned (see Section 3.1).

\subsection{Collective Cognition}

A recent focus of interest for the WAIS community relates to the use of Web technologies to support socially-distributed forms of cognition (Chi, 2008, 2009; Kearns, 2012); i.e., forms of cognition in which the relevant cognitive processes (e.g., reasoning, remembering and problem-solving) are distributed across a collection of individuals. This interest is reflected in a wealth of research relating to online socio-technical systems. The conceptual landscape of the Social Web is thus littered with terms like social computing (Parameswaran and Whinston, 2007), human computation (Law and von Ahn, 2011; Michelucci, 2013), collective intelligence (Bonabeau, 2009; Malone et al, 2010; Halpin, 2013), social machines (Hendler and Berners-Lee, 2010; Smart et al, 2014), technology-mediated social participation (Kraut et al, 2010), and the global brain (Heylighen, 2013). The purpose of these locutions is often to emphasize the way in which Web technologies can be used to harness the socio-cognitive potential of large numbers of physicallydistributed individuals.

Because of the kinds of opportunities it affords for large-scale collaboration, information sharing, and the coordination of collective efforts, the Internet seems to be ideally suited to supporting cases of collective cognition. Perhaps the best example of such support is provided by tasks that involve some form of collaborative problem-solving or collective decision making (Chi, 2009; Chi et al, 2008). In this case, the Internet is often used to support a form of 'virtual team-working', 17 , in which a collection of geographicallydistributed individuals rely on the network-mediated exchange of information as a means of coordinating their individual problem-solving efforts. Given the popularity of such forms of virtual team-working in a range of organizational settings (see Kanawattanachai and Yoo, 2002), it is perhaps not surprising

17 Virtual team-working is a form of team-working that relies on the use of information and communications technology to support task-relevant forms of information exchange, information processing and inter-agent coordination (see Powell et al, 2004). 
that this particular form of collective cognition has become a prominent focus of attention for those working in the disciplines of computer, cognitive and network science. Recent research has thus sought to understand the factors that regulate the performance of collective cognitive systems under a range of experimental conditions, with issues of network structure (i.e., the time-variant organization of communication network topology) emerging as a particularly important focus of empirical investigation (Kearns, 2012; Mason, 2013; Mason and Watts, 2012; Mason et al, 2008; Smart et al, 2010a). The kind of processing that is undertaken in the context of such systems is sometimes glossed as a form of 'socio-computational processing', a term that helps to highlight the important role that technologically-advanced computational systems play with respect to the mediation of social exchanges and the active processing of task-relevant information ${ }^{18}$.

The notion of virtual teams ${ }^{19}$ thus serves as an important example of how our existing notions of collective cognition - for example, work on group (Theiner, 2014) and team cognition (Cooke et al, 2007; Salas et al, 2011)can be applied to the online world. Virtual teams do not, however, exhaust the reach of the concept of collective cognition when it comes to understanding various forms of Internet-mediated activity. In some cases, the processes by which specific informational ecologies come into being on the Internet are themselves also described in distributed or collective cognitive terms. Consider, for example, the way in which the linking behavior of Internet users yields a body of information that can be used to support the operation of Internet search engines. The most popular example in this case, is, of course, the PageRank algorithm, as used by Google Search. Here, the editing actions of countless numbers of Internet users serves as the analytic substrate for machine-based processes that seek to enhance the accessibility of online information in a way that is aligned with the interests and concerns of the human user community. Heintz (2006) suggests that we should see such activities as a form of distributed (i.e., collective) cognition, one that (presumably) supervenes on the actions of a very large number of human individuals. Such claims are likely to prove controversial; however, Heintz's (2006) analysis does help to highlight the way in which a combination of human action and machine-based processing can play an important role in creating and config-

18 Although it is easy to see such forms of processing as a relatively recent phenomenon, it is important to remember that technologically low-grade variants of socio-computational processing date back to at least the 18th century (see Grier, 2013).

19 A virtual team, in this case, is simply a collection of individuals that engages in a form of virtual team-working (see Powell et al, 2004). Crucially, nothing in this definition rules out the possibility that a virtual team could (at different points in time) also function as a real-world (or face-to-face) team. The result is that any form of (conventional) team cognition is also (potentially at least) a form of virtual team cognition. Consider, for example, how collaborative sensemaking technologies (e.g., Shrager et al, 2010; Toniolo et al, 2014) might be used to support the kinds of analyses undertaken by (e.g.) criminal investigators (Baber, 2013). 
uring the online environment. A similar point is made by Smart and Shadbolt (in press) in regard to the social construction of 'reliability indicators'. Smart and Shadbolt suggest that the individual actions of many thousands of individuals helps to shape the kinds of cues and affordances that are available to guide the epistemic evaluation of online content. What is crucial here is the sense in which the social and technological components of some larger systemic organization are working to help shape and structure the nature of the online cognitive ecology - an ecology that then plays a significant role in sculpting the profile of our individual and collective cognitive endeavours.

Wikipedia is another example where one encounters this particular form of cognitively-potent 'ecological engineering'. In this case, the technical components help to shape and scaffold user contributions in such a way as to yield a rich and reliable source of information that is relevant to a broad range of epistemic activities (Fallis, 2011). Wikipedia is, in fact, emblematic of a broad range of systems, sometimes glossed as 'social machines' (Smart et al, 2014; Hendler and Berners-Lee, 2010), in which much of the online content is supplied or generated by human end-users. Even if we demur from the conclusion that the processes associated with such systems should be regarded as genuine cases of collective cognition, we can surely accept that such systems support a form of ecological engineering that is relevant to our individual and collective cognitive capabilities.

Inasmuch as systems like Google Search or Wikipedia count as cognitive systems, they are clearly systems that exist at a much larger scale than the kind of kind of cognitive systems that are the typical focus of distributed cognition research. This, by itself, however, need not be a cause for concern. As Hutchins (2014) himself suggests cognitive systems can exist at a variety of spatial and temporal scales. In the ecological context of the Internet, we can identify a variety of socio-technical systems that could be considered as potential candidates for cognitive scientific analysis. Such systems can be ranked according to their relative social size, or the number of individual human agents that typically participate in them. At the lower end of this scale, we encounter systems that can perhaps be broadly construed as virtual teams (see above). The size of these systems typically ranges from tens to hundreds of individuals. At larger scales, we encounter human computation systems ${ }^{20}$ (see Section 2) like Foldit (Khatib et al, 2011) and Galaxy Zoo (Lintott et al, $2008)^{21}$. These systems - and others like them (see Lintott and Reed, 2013)rely on the efforts of thousands of individuals in order to support the process

20 A human computation system, recall, is a system that combines human and machine capabilities to perform complex computational tasks (Law and von Ahn, 2011; Michelucci, 2013; Quinn and Bederson, 2011,?).

21 In the case of Foldit, human pattern matching and spatial reasoning abilities are used to help solve the problem of predicting the three-dimensional structure of selected proteins (Khatib et al, 2011). Galaxy Zoo, in contrast, relies on human visual pattern recognition to detect and classify galaxies from large-scale astronomical image databases (Lintott et al, 2008). 
of scientific discovery. Systems such as Wikipedia and Google Search exist at even larger scales. In the case of Wikipedia, for example, tens of thousands of individuals participate in the editing of online articles, and Google Search requires even larger numbers of individuals (hundreds of thousands to millions). Large-scale forms of social participation are often critical to the success of these systems: in the absence of large-scale social participation, for example, Wikipedia could not have the coverage it does, nor could it update its articles in a timely fashion. Both of these features are of obvious relevance to Wikipedia's status as a source of epistemically-significant information.

\section{Conclusion}

It is tempting to view the Internet as a globally-interconnected repository of data and information. This view of the Internet is not necessarily incorrect; however, it does not really do justice to the many ways in which the Internet shapes our actions and capabilities at both an individual and collective level. The Internet is thus not just an alternative way of disseminating information in a manner akin to that accomplished by our traditional print media (see Carr, 2010). Neither is the Internet merely "the next great extension of the 'external symbolic storage system' humans have developed since the beginning of civilization" (Staley, 2014, p. ix). The Internet is, in fact, many things. It is an instrument of social change, a mechanism for coordinating disaster relief efforts, a platform for scientific discovery, and a potential breeding ground for the next generation of AI systems. It is also (perhaps less positively) a tool for Distributed Denial of Service (DDoS) attacks on corporate Websites, a marketplace for the exchange of illicit goods, a vector for the transmission of extremist ideologies, and the future field of battle for warring nation states. The Internet is, in essence, an environment in which all manner of processes can occur and upon which many kinds of capabilities are founded.

When our attention is directed to the realm of human cognitive activity, we suggest the Internet plays an important role in shaping the nature of our cognitive processes. The Internet, we claim, forms an important part of the extra-organismic environment that shapes, scaffolds, supports, sustains and perhaps even realizes our cognitive processing routines. It is, in essence, an important part of the wider cognitive ecology in which our biological brains are situated.

The value of a situated approach to cognition is that it helps us to appreciate the many ways in which the Internet can impact our individual and collective cognitive capabilities. Understanding the nature of this influence is crucial. Even the most ardent advocate of neurocentrism would no doubt be willing to accept that the kind of environment in which a biological brain is situated says a great deal about the kinds of capabilities it can realize. A situ- 
ated approach to cognition can help to reveal the many ways in which the Internet may influence our cognitive profiles, either for good or ill. It also helps to focus our attention on the capabilities of cognitive organizations whose systemic boundaries are not necessarily those of the (biologically-based) individual agent (e.g., extended and collective cognitive systems). Finally, a situated approach helps to reveal the complex web of reciprocal influences that exist between the Internet and those who use it. Importantly, the cognitive ecology of the Internet is an environment of our own making. By virtue of our interactions with the Internet, we help to shape what the Internet is, what it can do, and what it may yet become. In this sense, we are all, as Sterelny (2003) suggests, 'ecological engineers': we are all engaged in a process of cognitive niche construction (see Clark, 2008), actively involved in the construction and configuration of a bio-external nexus of material resources that helps to influence the course of our cognitive processing and define the limits of our cognitive capabilities.

Acknowledgements Paul Smart's contribution to this work was supported by the U.S. Army Research Laboratory and the U.K. Ministry of Defence and was accomplished as part of the International Technology Alliance (ITA) Project under Agreement Number W911NF-06-3-0001. Some of the ideas contained in the chapter were presented by Richard Heersmink at a seminar at the Center for Human Interactivity of the University of Southern Denmark. Richard would like to thank Sune Steffensen for the invitation and the audience for helpful feedback. Richard would also like to thank John Sutton and Alexander Gillett for helpful discussion on the Internet and cognition. Robert Clowes wishes to acknowledge the support of Portuguese Fundação para a Ciência e Tecnologia grant /BPD/70440/2010 that made possible his contribution to this paper. All authors would like to thank two anonymous reviewers who provided detailed feedback and suggestions on an earlier version of the chapter.

\section{References}

Aglioti S, Smania N, Manfredi M, Berlucchi G (1996) Disownership of left hand and objects related to it in a patient with right brain damage. Neuroreport 8(1):293296

Anderson M (2003) Embodied cognition: A field guide. Artificial Intelligence 149(1):91-130

Arango-Muñoz S (2013) Scaffolded memory and metacognitive feelings. Review of Philosophy and Psychology 4(1):135-152

Baber C (2013) Distributed cognition at the crime scene. In: Cowley SJ, ValléeTourangeau F (eds) Cognition Beyond the Brain: Computation, Interactivity and Human Artifice, Springer-Verlag, London, UK

Baddeley A, Eysenck MW, Anderson MC (2009) Memory. Psychology Press, Hove, East Sussex, UK

Bateson G (1972) Steps to an Ecology of Mind. Jason Aronson Inc., London, UK

Ben-Naim J, Bonnefon JF, Herzig A, Leblois S, Lorini E (2013) Computer-mediated trust in self-interested expert recommendations. In: Cowley SJ, Vallée-Tourangeau 
F (eds) Cognition Beyond the Brain: Computation, Interactivity and Human Artifice, Springer-Verlag, London, UK

Biocca F (1999) The cyborg's dilemma: Progressive embodiment in virtual environments. In: Marsh JP, Gorayska B, Mey JL (eds) Humane Interfaces: Questions of Method and Practice in Cognitive Technology, Elsevier, Amsterdam, The Netherlands

Bonabeau E (2009) Decisions 2.0: The power of collective intelligence. MIT Sloan Management Review 50(2):45-52

Carr N (2010) The Shallows: How the Internet Is Changing the Way We Think, Read and Remember. Atlantic Books, London, UK

Chi EH (2008) The Social Web: Research and opportunities. Computer 41(9):88-91

Chi EH (2009) Augmented social cognition: Using Social Web technology to enhance the ability of groups to remember, think, and reason. In: 35th SIGMOD International Conference on Management of Data, Providence, Rhode Island, USA

Chi EH, Pirolli P, Suh B, Kittur A, Pendleton B, Mytkowicz T (2008) Augmented social cognition. In: AAAI Spring Symposium on Social Information Processing, Stanford, California, USA

Clark A (1997) Being There: Putting Brain, Body and World Together Again. MIT Press, Cambridge, Massachusetts, USA

Clark A (1999) Where brain, body, and world collide. Cognitive Systems Research $1(1): 5-17$

Clark A (2001) Mindware: An Introduction to the Philosophy of Cognitive Science. Oxford University Press, Oxford, UK

Clark A (2003) Natural-Born Cyborgs: Minds, Technologies and the Future of Human Intelligence. Oxford University Press, Oxford, UK

Clark A (2007) Re-inventing ourselves: The plasticity of embodiment, sensing, and mind. Journal of Medicine and Philosophy 32(3):263-282

Clark A (2008) Supersizing the Mind: Embodiment, Action, and Cognitive Extension. Oxford University Press, New York, New York, USA

Clark A (2010) Memento's revenge: The extended mind, extended. In: Menary R (ed) The Extended Mind, MIT Press, Cambridge, Massachusetts, USA

Clark A (2011) Finding the mind. Philosophical Studies 152(3):447-461

Clark A, Chalmers D (1998) The extended mind. Analysis 58(1):7-19

Clowes R (2015) Thinking in the cloud: The cognitive incorporation of cloud-based technology. Philosophy \& Technology 28(2):261-296

Clowes RW (2013) The cognitive integration of E-Memory. Review of Philosophy and Psychology 4(1):107-133

Cooke NJ, Gorman JC, Winner JL (2007) Team cognition. In: Durso FT, Nickerson RS, Dumais ST, Lewandowsky S, Perfect TJ (eds) Handbook of Applied Cognition, 2nd edn, John Wiley \& Sons, Chichester, UK

van Dijk J (2012) The Network Society, 3rd edn. Sage Publications Ltd, London, UK

Donald M (1993) Precis of origins of the modern mind: Three stages in the evolution of culture and cognition. Behavioral and Brain Sciences 16(4):737-791

Dourish P (2001) Where the Action Is: The Foundations of Embodied Interaction. MIT Press, Cambridge, Massachusetts, USA

Drain C, Strong RC (2015) Situated mediation and technological reflexivity: Smartphones, extended memory, and limits of cognitive enhancement. In: Scalambrino F (ed) Social Epistemology and Technology: Toward Public Self-Awareness Regarding Technological Mediation, Rowman \& Littlefield International, Lanham, Maryland, USA

Fallis D (2011) Wikipistemology. In: Goldman AI, Whitcomb D (eds) Social Epistemology: Essential Readings, Oxford University Press, New York, New York, USA

Floridi L (2011) The construction of personal identities online. Minds and Machines $21(4): 477-479$ 
Floridi L (2014) The Fourth Revolution: How the Infosphere is Reshaping Human Reality. Oxford University Press, Oxford, UK

Gallagher S (2005) How the Body Shapes the Mind. Oxford University Press, Oxford, UK

Gant D, Kiesler S (2001) Blurring the boundaries: Cell phones, mobility, and the line between work and personal life. In: Brown B, Green N, Harper R (eds) Wireless World: Social and Interactional Aspects of the Mobile Age, Springer, London, UK

Gemmell J, Bell G (2009) The E-Memory Revolution. Library Journal 134(15):20-23

Gemmell J, Bell G, Lueder R (2006) MyLifeBits: A personal database for everything. Communications of the ACM 49(1):88-95

Giere RN (2007) Distributed cognition without distributed knowing. Social Epistemology 21(3):313-320

Giere RN (2012) Scientific cognition: Human centered but not human bound. Philosophical Explorations 15(2):199-206

Goldin-Meadow S (2003) Hearing Gesture: How Our Hands Help Us Think. Harvard University Press, Cambridge, Massachusetts, USA

Greengard S (2015) The Internet of Things. MIT Press, Cambridge, Massachusetts, USA

Gregory RL (1993) Mind in Science: A History of Explanations in Psychology and Physics. Penguin Books Ltd, London, England

Grier DA (2013) Human computation and divided labour: The precursors of modern crowdsourcing. In: Michelucci P (ed) Handbook of Human Computation, Springer, New York, New York, USA

Halpin H (2013) Does the Web extend the mind? In: 5th Annual ACM Web Science Conference, Paris, France

Halpin H, Clark A, Wheeler M (2010) Towards a philosophy of the Web: Representation, enaction, collective intelligence. In: Web Science Conference, Raleigh, North Carolina, USA

Heersmink R (2015) Dimensions of integration in embedded and extended cognitive systems. Phenomenology and the Cognitive Sciences 14(3):577-598

Heersmink R (in press) The cognitive integration of scientific instruments: Information, situated cognition, and scientific practice. Phenomenology and the Cognitive Sciences

Heintz C (2006) Web search engines and distributed assessment systems. Pragmatics \& Cognition 14(2):387-409

Helmstaedter M, Briggman KL, Turaga SC, Jain V, Seung HS, Denk W (2013) Connectomic reconstruction of the inner plexiform layer in the mouse retina. Nature 500(7461):168-174

Hendler J, Berners-Lee T (2010) From the Semantic Web to social machines: A research challenge for AI on the World Wide Web. Artificial Intelligence 174:156-161

Heylighen F (2013) From human computation to the global brain: The selforganization of distributed intelligence. In: Michelucci P (ed) Handbook of Human Computation, Springer, New York, New York, USA

Hutchins E (1995) Cognition in the Wild. MIT Press, Cambridge, Massachusetts, USA

Hutchins E (2010) Cognitive ecology. Topics in Cognitive Science 2(4):705-715

Hutchins E (2011) Enculturating the supersized mind. Philosophical Studies 152(3):437-446

Hutchins E (2014) The cultural ecosystem of human cognition. Philosophical Psychology 27(1):34-49

Janssen JH, Bailenson JN, Ijsselsteijn W, Westerink JH (2010) Intimate heartbeats: Opportunities for affective communication technology. IEEE Transactions on Affective Computing 1(2):72-80 
Kanawattanachai P, Yoo Y (2002) Dynamic nature of trust in virtual teams. The Journal of Strategic Information Systems 11(3):187-213

Kearns M (2012) Experiments in social computation. Communications of the ACM 55(10):56-67

Khatib F, Cooper S, Tyka MD, Xu K, Makedon I, Popovic Z, Baker D, Foldit Players (2011) Algorithm discovery by protein folding game players. Proceedings of the National Academy of Sciences 108(47):18,949-18,953

Kirsh D, Maglio P (1994) On distinguishing epistemic from pragmatic action. Cognitive Science 18:513-549

Koriat A, Nussinson R (2009) Attributing study effort to data-driven and goal-driven effects: Implications for metacognitive judgments. Journal of Experimental Psychology: Learning, Memory, and Cognition 35(5):1338-1343

Kraut R, Maher ML, Olson J, Malone TW, Pirolli P, Thomas JC (2010) Scientific foundations: A case for technology-mediated social-participation theory. Computer 43(11):22-28

Kunze K, Iwamura M, Kise K, Uchida S, Omachi S (2013) Activity recognition for the mind: Toward a cognitive "quantified self". Computer 46(10):105-108

Landsness EC, Goldstein MR, Peterson MJ, Tononi G, Benca RM (2011) Antidepressant effects of selective slow wave sleep deprivation in major depression: A high-density EEG investigation. Journal of Psychiatric Research 45(8):1019-1026

Law E, von Ahn L (2011) Human computation. Synthesis Lectures on Artificial Intelligence and Machine Learning 5(3):1-121

Lintott CJ, Reed J (2013) Human computation in citizen science. In: Michelucci P (ed) Handbook of Human Computation, Springer, New York, New York, USA

Lintott CJ, Schawinski K, Slosar A, Land K, Bamford S, Thomas D, Raddick MJ, Nichol RC, Szalay A, Andreescu D, Murray P, van den Berg J (2008) Galaxy Zoo: Morphologies derived from visual inspection of galaxies from the Sloan Digital Sky Survey. Monthly Notices of the Royal Astronomical Society 389(3):1179-1189

Ludwig D (2015) Extended cognition and the explosion of knowledge. Philosophical Psychology 28(3):355-368

Lupton D (2013) Understanding the human machine. IEEE Technology and Society Magazine 32(4):25-30

Lupton D (2015) Digital Sociology. Routledge, Abingdon, Oxon, UK

Lynch MP (2014) Neuromedia, extended knowledge and understanding. Philosophical Issues 24(1):299-313

Maguire EA, Gadian DG, Johnsrude IS, Good CD, Ashburner J, Frackowiak RS, Frith CD (2000) Navigation-related structural change in the hippocampi of taxi drivers. Proceedings of the National Academy of Sciences 97(8):4398-4403

Malafouris L (2004) The cognitive basis of material engagement: Where brain, body and culture conflate. In: DeMarrais E, Gosden C, Renfrew C (eds) Rethinking Materiality: The Engagement of Mind with the Material World, The McDonald Institute for Archaeological Research, Cambridge, UK

Malafouris L (2013) How Things Shape the Mind: A Theory of Material Engagement. MIT Press, Cambridge, Massachusetts, USA

Malone TW, Laubacher R, Dellarocas C (2010) The collective intelligence genome. MIT Sloan Management Review 51(3):21-31

Marx V (2013) Neuroscience waves to the crowd. Nature Methods 10(11):1069-1074

Mason W (2013) Collective search as human computation. In: Michelucci P (ed) Handbook of Human Computation, Springer, New York, New York, USA

Mason W, Watts DJ (2012) Collaborative learning in networks. Proceedings of the National Academy of Sciences 109(3):764-769

Mason WA, Jones A, Goldstone RL (2008) Propagation of innovations in networked groups. Journal of Experimental Psychology: General 137(3):422-433 
Matsumoto T, Hashimoto S, Okude N (2008) The Embodied Web: Embodied Webservices interaction with an umbrella for augmented city experiences. Computer Animation and Virtual Worlds 19(1):49-66

Mayer-Schönberger V (2011) Delete: The Virtue of Forgetting in the Digital Age. Princeton University Press, Princeton, New Jersey, USA

McBeath M, Shaffer D, Kaiser M (1995) How baseball outfielders determine where to run to catch fly balls. Science 268(5210):569-573

Menary R (2010) Dimensions of mind. Phenomenology and the Cognitive Sciences 9(4):561-578

Michaelian K, Arango-Muñoz S (2014) Epistemic feelings, epistemic emotions: Review and introduction to the focus section. Philosophical Inquiries 2(1):97-122

Michelucci P (ed) (2013) Handbook of Human Computation. Springer, New York, New York, USA

Michelucci P (2016) Human computation and convergence. In: Bainbridge W, Roco M (eds) Handbook of Science and Technology Convergence, Springer, New York, New York, USA

Miller J (2014) The fourth screen: Mediatization and the Smartphone. Mobile Media \& Communication 2(2):209-226

Miller M (2015) The Internet of Things: How Smart TVs, Smart Cars, Smart Homes, and Smart Cities are Changing the World. Que Publishing, Indianapolis, Indiana, USA

Nersessian NJ (2009) How do engineering scientists think? Model-based simulation in biomedical engineering research laboratories. Topics in Cognitive Science 1(4):730757

Neumann M, Cowley SJ (2013) Human agency and the resources of reason. In: Cowley SJ, Vallée-Tourangeau F (eds) Cognition Beyond the Brain: Computation, Interactivity and Human Artifice, Springer-Verlag, London, UK

Oksman V, Rautianen P (2003a) Extension of the hand: Children's and teenager's relationship with the mobile phone in Finland. In: Fortunati L, Katz J, Riccini R (eds) Mediating the Human Body: Technology, Communication and Fashion, Lawrence Erlbaum, Mahwah, New Jersey, USA

Oksman V, Rautianen P (2003b) "Perhaps it is a body part": How the mobile phone became an organic part of the everyday lives of Finnish children and teenagers. In: Katz J (ed) Machines that Become Us: The Social Context of Communication Technology, Transaction Publishers, New Brunswick, New Jersey, USA

Parameswaran M, Whinston AB (2007) Research issues in social computing. Journal of the Association for Information Systems 8(6):336-350

Pfeifer R, Bongard J (2007) How the Body Shapes the Way We Think: A New View of Intelligence. MIT Press, Cambridge, Massachusetts, USA

Powell A, Piccoli G, Ives B (2004) Virtual teams: A review of current literature and directions for future research. The DATA BASE for Advances in Information Systems 35(1):6-36

Quinn A, Bederson B (2011) Human computation: A survey and taxonomy of a growing field. In: Annual Conference on Human Factors in Computing Systems (CHI'11), Vancouver, British Columbia, Canada

Robbins P, Aydede M (2009) A short primer on situated cognition. In: Robbins P, Aydede M (eds) Cambridge Handbook of Situated Cognition, Cambridge University Press, Cambridge, UK

Rupert R (2004) Challenges to the hypothesis of extended cognition. Journal of Philosophy 101(8):389-428

Salas E, Fiore SM, Letsky MP (eds) (2011) Theories of Team Cognition: CrossDisciplinary Perspectives. Routledge, New York, New York, USA 
Salerno S, Zamagni E, Urquizar C, Salemme R, Farn A, Frassinetti F (2012) Increases of corticospinal excitability in self-related processing. European Journal of Neuroscience 36(5):2716-2721

Shapiro L (2007) The embodied cognition research programme. Philosophy Compass $2(2): 338-346$

Shapiro LA (2011) Embodied Cognition. Routledge, Abingdon, Oxon, UK

Sharma VK, Sharma P, Deshmukh R, Singh R (2015) Age associated sleep loss: A trigger for Alzheimer's disease. Bulletin of Clinical Psychopharmacology 25(1):7888

Shrager J, Billman D, Convertino G, Massar JP, Pirolli P (2010) Soccer science and the Bayes community: Exploring the cognitive implications of modern scientific communication. Topics in Cognitive Science 2(1):53-72

Simpson TW (2012) Evaluating Google as an epistemic tool. Metaphilosophy 43(4):426-445

Smart PR (2012) The Web-extended mind. Metaphilosophy 43(4):426-445

Smart PR (2013) Understanding the cognitive impact of emerging Web technologies: A research focus area for embodied, extended and distributed approaches to cognition. In: 1st International Web for Wellbeing \& Human Performance Workshop, Paris, France

Smart PR (2014) Embodiment, Cognition and the World Wide Web. In: Shapiro LA (ed) The Routledge Handbook of Embodied Cognition, Routledge, New York, New York, USA

Smart PR (in press) Emerging digital technologies: Implications for extended conceptions of cognition and knowledge. In: Carter AJ, Clark A, Kallestrup J, Palermos OS, Pritchard D (eds) Extended Epistemology, Oxford University Press, Oxford, UK

Smart PR, Shadbolt NR (in press) The World Wide Web. In: Chase J, Coady D (eds) Routledge Handbook of Applied Epistemology, Routledge, New York, New York, USA

Smart PR, Sycara K (2015) Situating cognition in the virtual world. In: 6th International Conference on Applied Human Factors and Ergonomics, Las Vegas, Nevada, USA

Smart PR, Huynh TD, Braines D, Shadbolt NR (2010a) Dynamic networks and distributed problem-solving. In: Knowledge Systems for Coalition Operations (KSCO'10), Vancouver, British Columbia, Canada

Smart PR, Huynh TD, Braines D, Sycara K, Shadbolt NR (2010b) Collective cognition: Exploring the dynamics of belief propagation and collective problem solving in multi-agent systems. In: 1st ITA Workshop on Network-Enabled Cognition: The Contribution of Social and Technological Networks to Human Cognition, Maryland, USA

Smart PR, Simperl E, Shadbolt NR (2014) A taxonomic framework for social machines. In: Miorandi D, Maltese V, Rovatsos M, Nijholt A, Stewart J (eds) Social Collective Intelligence: Combining the Powers of Humans and Machines to Build a Smarter Society, Springer, Berlin, Germany

Sparrow B, Liu J, Wegner D (2011) Google effects on memory: Cognitive consequences of having information at our fingertips. Science 333(6043):776-778

Staley DJ (2014) Brain, Mind and Internet: A Deep History and Future. Palgrave Macmillan, Basingstoke, England, UK

Sterelny K (2003) Thought in a Hostile World: The Evolution of Human Cognition. Blackwell Publishing, Oxford, UK

Sterelny K (2010) Minds: Extended or scaffolded? Phenomenology and the Cognitive Sciences 9(4):465-481

Stewart JR, Gapenne O, Di Paolo EA (2010) Enaction: Toward a New Paradigm for Cognitive Science. MIT Press, Cambridge, Massachusetts, USA 
Sutton J (2006) Distributed cognition: Domains and dimensions. Pragmatics \& Cognition 14(2):235-247

Sutton J (2010) Exograms and interdisciplinarity: History, the extended mind, and the civilizing process. In: Menary R (ed) The Extended Mind, MIT Press, Cambridge, Massachusetts, USA

Sutton J, Harris C, Keil P, Barnier A (2010) The psychology of memory, extended cognition, and socially distributed remembering. Phenomenology and the Cognitive Sciences 9(4):521-560

Suzuki K, Garfinkel SN, Critchley HD, Seth AK (2013) Multisensory integration across exteroceptive and interoceptive domains modulates self-experience in the rubber-hand illusion. Neuropsychologia 51(13):2909-2917

Swan M (2013) The quantified self: Fundamental disruption in big data science and biological discovery. Big Data 1(2):85-99

Tasali E, Leproult R, Ehrmann DA, Van Cauter E (2008) Slow-wave sleep and the risk of type 2 diabetes in humans. Proceedings of the National Academy of Sciences 105(3):1044-1049

Theiner G (2014) Varieties of group cognition. In: Shapiro LA (ed) The Routledge Handbook of Embodied Cognition, Routledge, New York, New York, USA

Theiner G, Allen C, Goldstone RL (2010) Recognizing group cognition. Cognitive Systems Research 11:378-395

Toniolo A, Ouyang RW, Dropps T, Allen JA, Johnson DP, de Mel G, Norman TJ, Oren N, Srivastava M (2014) CISpaces, towards a system for online collaborative argument construction and debate. In: International Workshop on Arguing on the Web 2.0, Amsterdam, The Netherlands

Tribble E, Sutton J (2011) Cognitive ecology as a framework for Shakespearean studies. Shakespeare Studies 39:94-103

Valins S (1966) Cognitive effects of false heart-rate feedback. Journal of Personality and Social Psychology 4(4):400-408

Vallar G, Ronchi R (2009) Somatoparaphrenia: A body delusion. A review of the neuropsychological literature. Experimental Brain Research 192(3):533-551

Van Kleek M, O'Hara K (2014) The future of the social is personal: The potential of the personal data store. In: Miorandi D, Maltese V, Rovatsos M, Nijholt A, Stewart J (eds) Social Collective Intelligence: Combining the Powers of Humans and Machines to Build a Smarter Society, Springer, Berlin, Germany

Vincent J, Haddon L, Hamill L (2005) The influence of mobile phone users on the design of $3 \mathrm{G}$ products and services. The Journal of the Communications Network $4(4): 69-73$

Vygotsky LS, Luria AR (1994) Tool and symbol in child development. In: Van Der Veer R, Valsiner J (eds) The Vygotsky Reader, Basil Blackwell, Cambridge Massachusetts, USA

Webb B (1996) A cricket robot. Scientific American 275(6):94-99

Weber W, Rabaey JM, Aarts E (2005) Ambient Intelligence. Springer, Berlin, Germany

Wegner DM (1995) A computer network model of human transactive memory. Social Cognition 13(3):319-339

Weiser M (1991) The computer for the 21st century. Scientific American 265(3):94104

Williamson K, Sutton J (2014) Embodied collaboration in small groups. In: Wolfe CT (ed) Brain Theory: Essays in Critical Neurophilosophy, Palgrave Macmillan, Basingstoke, England, UK

Wilson RA, Clark A (2009) Situated cognition: Letting nature take its course. In: Robbins P, Aydede M (eds) Cambridge Handbook of Situated Cognition, Cambridge University Press, Cambridge, UK 
Won AS, Bailenson J, Lee J, Lanier J (2015) Homuncular flexibility in virtual reality. Journal of Computer-Mediated Communication 20(3):241-259

Woods SP, Iudicello JE, Moran LM, Carey CL, Dawson MS, Grant I (2008) HIVassociated prospective memory impairment increases risk of dependence in everyday functioning. Neuropsychology 22(1):110-117 